\title{
BUDAYA AMONG-AMONG DAN SLAMETAN DI PULAU JAWA
}

\section{Oleh: Muhammad Rayhan Hidayatullah}

\author{
Prodi Studi Agama-agama Fakultas Ushuluddin \\ Universitas Darussalam Gontor \\ rayhanhid03@gmail.com
}

\begin{abstract}
ABSTRAK
Setelah agama islam masuk ke Indonesia pada abad 7-13 $M$, terjadi perubahan yang sangat drastis dalam system kepercayaan masyarakat Indonesia umumnya dan masyarakat jawa pada khususnya, karena islam berhasil perlahan mengambil hati masyarakatnya. Perkembangan dakwah islam di jawa memiliki proses yang unik, karena menghadapi kekuatan pra islam yang telah mengakar pada setiap spektrum kehidupan masyarakat. Para penyebar agama islam di pulau jawa tidak mudah untk menghilangkan dan menggeser budaya budaya yang telah diciptakan nenek moyang mereka pada masa pra islam. Maka dengan bentuk dan cara yang telah mengakar dalam kehidpan masyarakat tetap dipertahankan dengan arah dan tujuan dialihkan menuju yang bernuansa islami. Tetapi seiring berkembangnya zaman, budaya budaya masyarakat pulau jawa mengalami revolusi dalam bentuk, tata cara, dan tujuan pelaksanaanya. Sehingga tidak lagi dapat dikatakan sebaggai ajaran islam yang sesuai dengan apa yang tertera dalam Al Quran dan Hadist. Dalam artian bahwa budaya-budaya tersebut sudah tergolong dalam perbuatan yang syirik. Maka makalah ini mengkaji tentang budayabudaya masyarakat pulau jawa khususnya among-among yang telah mengalami revolusi bentuk, tatacara, dan tujuan pelaksanaan, yang sudah tidak sesuai dengan syareat islam.
\end{abstract}

\section{PENDAHULUAN}

Kebudayaan merupakan pendorong tingkah laku manusia dalam kehidupanya. Kebudayaapun menyimpan nilai nilai yang menjadi landasan pokok sebagai penentu sikap terhadap dunia luar. Bahkan menjadi dasar tingkah laku yang dilakukan sehubungan dengan pola hidup di masyarakar. Nilai-nilai yang luhur dari kebudayaan inilah yang diwariskan turun menurun dari generasi ke generasi lalui berbagai adat-istiadat yang khusus ${ }^{1}$.

Kebudayaan berasal dari Bahasa sansekerta buddaya, yang merupkan bentuk jamak dari buddhi, yang berarti budi dan akal. Maka kebudayaan diarikan dengan hal-hal yang berkaitan dengan budi dan akal. Sedangkan kebudayaan dari aspek kesenian diartikan sebagai ciptaan dari pola fikir dan perilaku yang fungsional, indah, estetis, sehingga dapat dinikmati oleh panca inderanya (pendengar, penglihatan, perasa, peraba, dan penciuman)².

Indonesia merupakan negara kepulauan dengan beraneka ragam Bahasa dan budaya. Di dalamnya tentu terdapat budaya dan adat-istiadat yang berbeda-beda. Salah satunya adalah budaya jawa. Budaya jawa menggambarkan pancaran budi masyarakat jawa yang mencakup: ide-ide, cita-cita masyarakat jawa dalam rangka tercapainya keselamatan, kemuliaan, dan kebahagiaan lahir dan batin. Dalam segala perkaembanganya, kebudayaan jawa masih pada hakikatnya. Kebudayaan masyarakat jawa yang berdomisili di daerah lain masih juga disebut sebagai subvariasi ddari kebudayaan jawa tersebut.

\footnotetext{
${ }^{1}$ Jacobus Ranjabar. Sisiem Budaya Indonesia Suatu Pengantar. (Bandung: Alfabeta 2016), 28

${ }^{2}$ Koentjaraningrat. Pengantar Antropologi II. (Jakarta: PT Rineka cipta 2018), 26
} 
Masyarakat jawa sangat kental akan tradisi dan adat-istiadat yang diwariskan nenek moyang mereka. Terutama masyarakat jawa yang mayoritas agama islam, tidak dapat meninggalkan budaya dan tradisi jawanya. Dintara tradisi dan budayanya adalah kepercayaan terhadap roh-roh ghoib, selametan, ziarah makam orang tertentu, melakukan ritual tertentu denan maksud mendapatkan berkah dn pertolonan dari roh orang tersebut, serta tradisi among-among yang bertujuan untuk doa dan keselamatan dari hal-hal yang nyata maupun ghoib ${ }^{3}$.

Keragaman budaya sudah menjasi ciri khas bangsa Indonesia. Budaya ini berasal dari nenek moyang bangsa Indonesia yang memegang erat budaya budaya mereka dan mewariskanya kepada anak keturunan mereka. Di samping perkembangan kebudayaan, islam mulai berkembang di pulau jawa. Kondisi kebudayaan masyarakat jawa yang sudah tertanam pada setiapa aspek kehidupannya menuntut kecerdasan, kearifan dan kebijaksanaan para da" $i$ untuk menggunakan cara yang diterapkanya. Sejarah mencatat, bahwa para wali dalam menyampaikan dakwahnya terbagi menjadi dua kelompok, yaitu Islam putihan dan abangan 4 . Islam putihan menampilkan dakwahnya sesuai dengan ajaran Nabi Muhammad SAW. Gerakan dakwah ini dimotori oleh Sunan Kudus, Sunan Giri, Sunan Ampel, Sunan Drajat, Sunan Gunung Jati dan Sunan Maulanan Malik Ibrahim. Sementara Islam abangan menampilkkan wajah islam yang santun, toleran, moderat, dan lentur serta tidak kaku kepada masyarakat yang masih awwam, kelompok ini dikomandani oleh Sunan Kalijaga, Sunan Muria dan Sunan Bonang. Meski berbeda cara dakwahnya tetapi secar subtansial ketauhidan atau keislamanya adalah sama. Para wali itu dalam menyebarkan islam tidak melalui missioneer, tidak pula menyebarkan secara langsung nilai-nilai asli dalam ajaran islam., tetapi melalui hubunganhubungan pribadi dan berbagai kegiatan Pendidikan. Dengan berbagai metode dakwah seperti: sikapnya yang santun, toleran serta moderat itu, islam berkembang pesat ke pelosok tanah air. Berkembangnya islam di pulau jawa adalah bukti keberhasilan metode yang digunakan walisongo dalam menyebarkan islam. Di sisi lain metode yang di gunakan wali songo memiliki sisi negative. Sikap toleran yang diterapkan oleh para wali songo terhadap kebudayaan yang tertanam di setiap aspek kehidupan masyarakat jawa membuat ajaran islam mengalami akulturasi dengan kebudayaan tersebut. Nilai nilai islam yang asli tidak berhasil dimasukan kepada hati setiap masyarakat jawa, bahkan, dalam peribadatan islam sudah terakulturasi dengan budaya jawa. Salah satu budaya jawa yang sudah suadah tertanam dalam peribadatan adalah budaya among among atau yang biasa dikenal dengan budaya selametan.

\section{ARTI AMONG-AMONG}

Among-among berasal dari kata dalam Bahasa jawa "pamomong" yang artinya ngemong, penjaga, pelindung, dan pengasuh jiwa raga. Among-among merupakan wujud doa untuk seseorang yang masih hidup yang bersifat individu. Secara singkat dapat digambarkan bahwa among among adalah tradisi makan bersama antar beberapa orang anak kecil atau orang dewasa. Tradisi memiliki cara yang unik, dimana nasi putih, sayuran, dan lauk pauk ditaruh di sebuan nampan dengan penataanya yang sedemikian rupa. Ada yang makan memakai piring ataupun daun pisang. Nampan tersebut diletakkan di tengah dengan anak anak ataupun orang dewsa yang melingkarinya. Kemudian berdiri seseorang yang memiliki hajat atau kemauan untuk menyampiaikan hajatnya dan meminta doa agar hajatnya segera terkabul dan mendapat keberkahan. Tradisi itu diakhiri dengan memakan bersama makanan

\footnotetext{
${ }^{3}$ franz magnis-Suseno. Etika Jawa Sebuah Analisi Filsafat Tentang Kebijaksanaan Hidup Jawa. (Jakarta: PT Gramedia Pustaka pusat 1984), 11.

${ }^{4}$ Jarman Arroisi. "Membaca Tradisi dan Budaya Sinkretis Masyarakat Jawa", Al-Hikmah: Jurnal AgamaAgama. Vol. 1, No. 1. (Ponorogo:2015).
} 
yang telah disediakan. Akan tetapi tradisi among-among telah banyak megalami perubahan. Tetpi perubahan tersebut tidak mengubah hakekat tujuan tradisi among among tersebut.

\section{SEJARAH AMONG-AMONG}

Menurut salah seorang tokoh masyarakat, tradisi among among bermula ketika sunan kalijaga menyebarkan agama islam di pulau jawa. Karena menghadapi tradisi sesajen masyarakt jawa yang sudah tertanam kuat, yang pada masa pra islam digunakan untuk persembahan kepada roh-roh ghoib, sunan kalijaga mengubah bentuk sesajen itu menjadi sebuah hidangan yang terdiri dari: nasi putih, sauran, dan juga lauk pauk.

Tradisi among-among ini muncul pada masa kekuasaan sultan agung dari kerajaan mataram atas ajran Raden Sahid atau Sunan Kalijaga. Dalam berdakwah Sultan Agung mengikuti jejak Suan Kalijaga, yaitu dengan cara pendekatan kultur budaya yang ada di jawa. Untuk menarik perhatian masyarakat, dia mencoba untuk memadukan sajin yang da dalam masyarakat dengan dakwah islam. Yang kemudian dikenal dengn istilah among-among.

Dalam kehidupan masyarakast jawa among-among juga disebut juga selamatan, karena tujuan pelaksanaanya agar mempeeroleh keselamatan hidup dunia dan akhirat. Selametan merupakan suatu acara makan bersama yang hidangannya sudah didoakan sebelum dihidangkan. Selamatan dapat digolongkan menjadi berbagai macam varian yang setiapa pelaksanaanya berbeda arah dan tujuan. Keenam varian tersebut dilaksnakan pada peristiwa yang berbeda dalam rangka lingkaran hidup seseorang, yaitu; kehamilan, kelahiran, upacra memotong rambut pertama, upacara menyentuh tanah pertama, upacara pernikahan, dan upacara kematian atau setelah kematian. Adapun selametan yang lain seperti: selametan setelah perjalanan jauh, selametan menempati rumah baru, dan selametan setelah sembuh dari penyakit.

Pada dasarnya masyarakat jawa tidak mempercayai adanya roh-roh goib yang mengganggu manusia. Tetapi mereka mempercayai adanya roh-roh yang menyertainya dalam segala aspek kehidupan manusia serta mengarahkan manusian untuk melakukan perbuatan baik dan menghindari perbuatan yang murka. Dalam istilah jawa roh tersebut disebut sebagai pamomong (yang mengasuh). Pembuatan among-among dipercayai sebagai ungkapan terimakasih orang tua untuk yang menjaga anak-anknya. Masyarakat jawa adalah masyarakat yang selalu mempertimbangkan segala sesuatunya. Mereka berusaha untuk menyeimbangkan antara alam nyata dan alam ghoib. Mereka mempercayai bahwa dalam keseimbangan tersebut akan tercipta kehidupan yang harmonis dan dinamis.

\section{TRADISI AMONG-AMONG DALAM SIKLUS KEHIDUPAN}

1. Upacara kehamilan

Jika seorang ibu hamil pertama, agar janinya selamat biasanya diadakan upacara amomngamong atau selametan. Biasanya upacara among-among untuk upacara kehamilan diadakan pada saat umur janin menginjak usia lima, tujuh, atau Sembilan bulan. Upacara among-among dalam setiap waktunya tersebut oberampe yang digunakan berbeda-beda. Dalam pelaksanaanya, sebelum menghidangkan hidangan pada saat iu upacara ngilimani dimulai. Sohibul bait atau yang punya hajat atau kehendak menyampaikan tujuan diadakanya acara trsebut supaya bayi yang ada di janin si ibu dapat selamat, sehat dan sesuai yang diinginkan orangtuanya. ${ }^{5}$

\section{Upacara kelahiran}

\footnotetext{
${ }^{5}$ Jarman Arroisi. Aliran Kepercayaan Kebatinan dan Sinkretism, (Ponorogo: UNIDA Gontor Press), 95
} 
Lain halnya dengan upacara kehamilan, upacara kelahiran lebih ragam macamnya. Ada yang memulai dengan penanaman ari-ari yang sudah dibersihkan sebelumnya. Ari-ari itu yang sudah dibersihakan itu biasanya diletakkan didalam kendil kecil disertai dengan bacaan Al Quran.Ari-ari tersebut tidak boleh ditanam disembarang tempat, mekainkan di tempat yang aman. Bahkan tempat ari -ari ditanam basanya diberi lampu penerang agar selalu terjaga.

Upacara slametan yang dislenggarakan pada saat bayi baru lahir di sebut brokohan. Hidangan yang dihidangkan pada upacara brokohan ini berbeda dengan upacara kehamilan, dalam upacara brokohan ini biasanya uboranpe yang yanf disiapkan adalah nasi putih dan sayur kacang Panjang. brokohan merupakan upacara kesyukuran yang diadakan setelah bayi dilahirkan dengan maksud agar si bayi mendapatkan brokoh atau berkat dari Allah SWT. Pada siang hari biasanya oara tetangga yang erdiri dari ibu-ibu dan prempuan berdatngan untuk sekedar melihat kondisi bayi yang baru lahir. Sedangkan para laki-laki yang terdiri dari bapakbapak biasanya dating pada malam hari dengan mendadakan acara jagongan semalam suntukselama Sembilan hari disertai dengan main judi. ${ }^{6}$

\section{Upacara perkawinan}

Setelah bayi menginjak dewasa dan ingin hidup berumah tangga biasanya masyrakat jawa mengadakan upacara slematan. Dalam menggelar uacara slametan untuk pernikahan, orang yang berhajat trlebih dahulu harus memenuhi persyarakatan-persyaratan. Diantaranya adalah menentukan hari baik untuk diadakanya slametan. Dalam menentukan hari baik, biasanya masyarakat jawa merujuk poada pedoman pancasuda ${ }^{7}$. Dalam primbon pancasuda ini terdapat rumus untuk menentukan hari yang baik dan layak untuk diadakanya slametan.

Dalam ehidupan masyarakat jawa, upacara slematan pernikahan lebih familiar dengan nama mantenan atau dadi temanten. Dalam tradisi mantenan ini biasanya waktu dan tatacara pelaksanaanya mengikutu aturan yang telah dibangun oleh nenek moyang. Waktu yang ditentukan untuk perkawina tidak dipilh secara sembrono atau sewena-wena. Dalam kepercayaan mereka pabila wktu yang ditentukan adalah hariyang baik maka kehidupan mempelai wanita dan laki-laki setelah perkawinan akan baik dan mendapatkan kebahagiaan sebliknya, apabila hari yang ditentukan adalah hari yang tidak baik maka keduanya akan segara mendapatkn cobaan dan musibah dalam kehidupanya.

\section{Upacara kematian}

Upacara slametan juga diadkan pda hari kematian seseorang. Dalam upacara ini disertaan sesaji lenkap. Besar kecilnya upacara slametan bergantung pada kemampuan yang ditinggalkan. Apabila keluarga yang ditinggalkan merupakan keluarga yang kaya maka upacara slametan akan diadakan dengan besar-besaran. Sebaliknya, apabil keluarga yang ditinggalkan merupakan kelurga bertaraf menengah ke bawah, maka slametan akan diadakan secara sederhana. Upacar slametan kematian pada tradisi jawa sangat banyak ragamnya. Ada slametan hari ke 1, ke 3, ke 7, ke 40, ke 100, dan yang terakhir slametn hari ke 1000.

Untuk upacar hari pertama setelah kematian, setelah yang meninggal selesai dilebumikan kurang lebih lima jam sampai tujuh jam akan diadakan slametan sesederhana mungkin. Dalam upacara slametan hari pertama biasanya tamu yang diundan hanya tetangga sekitar rumah saja. Upacara ini dilasanakn dengandoa dengan maksud agar arwah orang yang meninggal dunia dapat hidup dengan tenang di aam lain serta amala amalannya di dunia dapat diterima

\footnotetext{
${ }^{6}$ Ibid hal 97-98

${ }^{77}$ Hitungan pancasuda merupakan hitungan porimbon yang digunakan untuk mengungkapakan rahasia hidup berdasarkan ramalan yang beraneka ragam. Jika seseorang hendak mngadakan hajatn dan brhara atas hasil yang bik, maka trlebih dahulu mencari hari yang cocok untk hajatan trsebut.
} 
disisi yang Maha Kuasa. Di akhir acara ini tamu yang diundang dipersilahkan pulang dengan membawa berkat yang biasanya terdiri dari: nasi uduk, ingkung, telur, mie instan daln lain sebagainya tergantung taraf kehidupan keluarga yang mengadakan.

\section{Tradisi Slametan Alam}

Yang dimaksudkan dengan upacara slametan alam disini adalah upacar yang diadakan masyaraat jawa di tempat-tempat ertentu yang memiliki kekuatan magis dan supranatura. Tidak sedikit masyarakt muslim jawa yang mengadapakn acara ini bahkan pada tingkatan wajib. Diantara dari berbagai upacara tersebut adalah: wiwit atau upacara menanam padi, Nyadran yang diadaka setiap hari kamis kiwin dan juga upacara yang diadakan di kuburan yang lebih dikenal dengan nama danyang dan lain sebagainya.

\section{Tradisi Slametan ziarah}

Tradisi selametan ziarah yang dimaksud disini adalah kebiasaan melakukan upacara atau selametandi beberapa tempat yang dianggap keramat atau memiliki kekuatan goib. Acara ini biasanya diadakan setahun sekali. Dan waktu pelaksanaanya biasanya sama seperti sholat jumat. Maka apabila hari yang meraka nantikan itu telah tiba biasanya masyarakt jawa dengan penuh kebahagiaan mengikuti acara ini dengan khidmat. Pada upacara ini, masing masing keluarga membawa uang sedekah yang akan diberikan kepada pepunden atau orang yang telah berjasa pada babat desa. Dengan penuh keyajkina dan harapan, mereka mulai berdatangan satu persatu dari seluruh penjuru desa. Dengan membawa uang sedekah masing masing. Dengan pakaian yang rapi dan dandanan yang seinadah mungkin meraka tiba layaknya orang orang yang pergi hajatan. Tanpa dikomando mereka segera mengelilingi makam yang dianggap keramat. Beberapoa waktu kemudian Ketika dirasa sudah tidak ada orang yang tertinggal upacara ini dimulai. Dengan suara hening mereka mendengarkan sambutan dari pujangga desa atau juru slamet yang berugas menyampoaikan acara ini. Juru slamet menjelaskan pentingnya acara ini diadakan sebagai srana meraih ketenangan, ketentraman dan kabahagiaan hidup. Setelah selesai sambutan, acara ini diakhiri dengan doa dari jur slamet, serta para anggota keluaraga yang meengaimini setiap doa yang teetutur dari mulut juru slamet tersebut. Setelah selesai doa masing masing anggota leuarga dipersilahkan untuk memakan hidangan yang mereka bawa dari rumah. Sebelum beranjak dari makam mereka memasukan uang yang mereka bawa dari rumah ke dalam baskom (baki yang berbentuk bundar). Uang yang terkumpul dari warga tersebut yang nantinya akan digunakan untuk membangun dan memajukan desa.

\section{Among-among turun tanah}

Among-among turun tanah merupakan adat budaya yang dilaksanakan sebagai penghormatan kepada bumi tempat anak mulai belajar menginjakan kakinya ke tanah. Selain itu among-among diringi dengan doa-doa dari orang tua dn sesepuh sebagai pengharapan agar kelak anak sukses menjalani kehidupanya. Yaitu bertujuan agar anak tumbuh menjadi anak yang mandiri.

Tradisi tarun anah (mudun lemah) dilakukan ketika anak menginjak usia 7 atau 8 bulan, anak laki-laki 7 bulan sedangkan anak perempuan 8 bulan. Tradisi ini tidak hanya di pulau Jawa saja. Tetapi juga di lakukan oleh suku jawa yang tinggal di berbagai daerah di Indonesia. Turun tanah menjadi simbol bagi kalangan msyarakat jawa dalam mengisyaratkan bahwaseorang anak sudah saatnya untuk kembali ke tanah, tradisi ini dilakukan sebagai upaya pendekatan kepada diri sendiri yang berunsur dari tanah.

\section{ISLAM DAN BUDAYA JAWA}


Nabi Muhammad SAW pernah berpesan, jangan sampai diantara umat islam yang memperingati hari kelahiranya sama seperti umat Nasrani memperingati hari kelahiran Isa AlMasih. Bahkan dengan tegas beliau menyatakan, saya ini hanyalah hamba biasa. Namun seiring berjalanya waktu pesan tersebut diabaikan dn dilupakan oleh sebagian umatnya, dengan menjadikan dan memperingati 12 Rabiul awwal sebagai hari kelahiran Nabi Muhammad SAW. Hari peringatan itu dalam masyarakat jawa lebih dikenal dengan maulid nabi Muhammad SAW.

Di sisi lain, masyarkat islam di pulau jawa terbiasa untuk meperingati hari kelahiran, hari kematian, hari pernikahan dan lain sebagainya. Tntu saja yang seperti ini tidk ada dalam syareat islam dan tidak ada dalil-dalil yang menjadi landasan dalam pengadaan hari-hari peringatan tersebut. Tentu saja mengadakan hari-hari peringatan tersebut atau yang lebih dikenal dengan budaya selametan bukan meruakan ajaran yang diperintahkan oleh Allah dan Rasul-Nya.

\section{KESIMPULAN}

Budaya among atau yang leblh di kenal dengan Slametan merupakan adat-istiadat jawa yang diwariskan dari nenek moyang leluhur mereka. Dalam menghadapi ajarn isam yang telah mengakar ada setiap aspek kehidupan masyarakat, budaya ini mengalami akulturusi dengan ajaran islam. Berawal dari masa sunan kalijaga yang menebarkan islam di pulau jawa Tanpa ingin mengubah kebudayaan yang telah di wariskan leuhur mereka. Budaya ini di campur dengan unsur unsur isam dalam masa revolusinya.

Budaya among merupakaan budaya yang branekaragam jenisnya dan tata cara pelaksanaanya. Diantaranya adalah: uppacara kehamilan, uacara kematian, upacara pernikahan, ziarah ke tempat tempat yang dianggap keramat. Dalam sistematika peleksanaana, setiap upacara diadakan dengan cara yang berbeda-beda dan hidangan yang berbeda beda. Setiap hidangan yang akn dihidangkan dalam upacara tersebut memiliki arti dan makna yang berbeda beda. Besar atau kecilnya cara yang digelr bergantung pada taraf kehidupan orang yang mengadakan.

\section{DAFTAR PUSAKA}

Arroisi, Jarman. 2015. "Membaca Tradisi dan Budaya Sinkretis Masyarakat Jawa". AlHikmah: jurnal agama-agama. Vol:1, No. 1

Arroisi, Jarman. 2019. Aliran Kepercayaan Kebatinan dan Sinkretism. Ponorogo: UNIDA Gontor Press.

franz magnis-Suseno. 1984. etika Jawa Sebuah Analisi Filsafat Tentang kebijaksanaan hidup jawa. Jakarta: GramediaPustaka pusat.

Koentjaraningrat. 2018. Pengantar Antropologi II. Jakarta: PT rineka cipta.

Ranjabar, Jacobus. 2016. Sisiem budaya Indonesia suati pengantar. Bandung: Alfabeta. 